\title{
QUALITY ANALYSIS OF MEATS USING FTIR SPECTROSCOPY, COLOUR SPECTROPHOTOMETER, TEXTURE ANALYSER AND PHYSICAL IMAGE ANALYSIS
}

\author{
AINUR NALISA ABD RASHID ${ }^{1}$, FARIDAH KORMIN ${ }^{1}$ AND SALIZA ASMAN*2,3 \\ ${ }^{1}$ Department of Technology and Natural Resources, ${ }^{2}$ Department of Physics and Chemistry, ${ }^{3}$ Advanced Analytical and \\ Environmental Chemistry (AdEC), Faculty of Applied Sciences and Technology, Universiti Tun Hussein Onn Malaysia, \\ Education Hub Pagoh, 84600, Pagoh, Johor, Malaysia.
}

*Corresponding author: salizaa@uthm.edu.my

Submitted final draft: 6 June 2020 Accepted: 13 June 2020

http://doi.org/10.46754/jssm.2021.01.010

\begin{abstract}
Assessment methods of meat such as physicochemical analyses and microbial techniques are laborious and time-consuming. A rapid and non-destructive quality analysis method of meat is needed and important to satisfy consumer demand. This study aims to implement FT-IR spectroscopy, colour spectrophotometer, texture analyser and physical image analysis to analyse the quality of raw, boiling and roasting meat. The FT-IR analysis revealed the functional group for proteins, triglycerides, fatty acids and carbohydrates with different intensities mostly focused at $3300 \mathrm{~cm}^{-1}, 2967 \mathrm{~cm}^{-1}, 1639 \mathrm{~cm}^{-1}, 1546 \mathrm{~cm}^{-1}, 1453$ $\mathrm{cm}^{-1}$. Colour parameters showed slight alterations and partial degradation of some proteins in meat was observed. $L^{*}, a^{*}$ and $b^{*}$ for raw meats decreased, $L^{*}$ and $b^{*}$ for boiled and roasted meats increased, and $\mathrm{a}^{*}$ decreased. The texture analysis shows significant different tenderness of meats and even cooking methods. Tenderness of raw meats decreased while the cooked meats increased from the first until the fifth day. The image analysis shows no significant changes in the meat textural surface. The findings show that the quality of cooked meats was better than raw meats. The assessment methods applied can evaluate the quality of meats and provide additional information on the physical changes of meat composition and structure.
\end{abstract}

Keywords: Beef, chicken, FTIR, colour spectrophotometer, texture analyser, physical image analysis.

\section{Introduction}

Meat quality has become more significant in meat industries as the rapid growth of pathogenic bacteria within meats may form surface slime, degradation of structural components, cause off-odours, off-flavours and change in meat appearance (Chen et al., 2020). Spoilage and contamination of vulnerable meats can subsequently have effects on both producers and consumers. For instance, contamination from pathogenic bacteria as well as fungal may cause foodborne illnesses among consumers. According to Mutawakil (2011), the quality of meats can reduce quickly due to contamination that may be caused by oxidation and enzymatic autolysis.

Analysis of meat is much needed to ensure the compliance of the legal quality assurance standard. The previous study has shown that traditional quality assessment methods of meat are always implied such as by sensory evaluation of meats and microbial techniques (Zhou et al., 2010). The most common detection method on quality assessment of meat is by using physicochemical analyses and microbial techniques (Herrero et al., 2017). Nevertheless, these methods have a major limitation such as being very laborious and time-consuming with high cost needed as in requiring a tremendous amount of samples. Therefore, it is required to introduce a fast, cost-effective, reagent-free and non-destructive methods to detect meat spoilage effectively. In the last year, alternative approaches based on vibrational spectroscopy have been developed.

In this regard, Fourier Transform Infrared Spectroscopy (FT-IR) is used as a quick and noninvasive method for detecting meat spoilage. 
FT-IR spectroscopy has shown its potential to predict any functional group changes in meat substrates and might extract valuable data regarding the muscle decomposition and substance generation due to the onset of spoilage (Rahman et al., 2016). Hence, FT-IR spectroscopy is believed to be one of the most effective methods for meat characterisation. The previous study showed the FT-IR analysis reveals the presence of absorbance bands of proteins, triglycerides, fatty acids, and others with different intensities according to meat type and processing (Dixit et al., 2017).

Apart from that, meat quality is closely related to its colour and texture. Colour plays a vital role in determining the quality of meat products (Jackman et al., 2011). Accordingly, the colour spectrophotometer can be used to examine the quality of meat which will give wavelength spectra analysis of the transmitted characteristics of the samples directly. It can provide enough data on colour values for any colour differences under a different light source. Standard meat colour measurement performed by colorimeter gives the direct benefit of tristimulus data $\left(\mathrm{L}^{*}\right.$ for lightness, $\mathrm{a}^{*}$ for redness and $\mathrm{b}^{*}$ for yellowness).

Besides, the texture analyser can evaluate and distinguish the texture and tenderness of all types of meats according to processing types. Tenderness of meat also is one of the most essential quality parameters that must be taken seriously as too tough and soft meats may cause lower quality. Texture analysis of meats focused on evaluating the tenderness or toughness differences of meats with different types. Meanwhile, the study on the physical image analysis can differentiate the texture and surface appearances of meat samples.

This study implements FT-IR, colour spectrophotometer, texture analyser, and physical image methods to analyse beef (m.longissimus dorsi) chops and chicken (m.pectoralis major) breast and their shelf-life at freezing temperature storage $(0)$ for five days. Two examples of the cooking method atse were chosen: the boiling process represents moist heat treatment and the roasting process represents dry heat treatment to identify the effect of cooking and processing with freezer storage on the quality of the meat. This study aims to use FTIR, colour spectrophotometer, texture analyser and physical image analysis to analyse the quality of raw meat and cooked meat (beef and chicken) by different cooking methods i.e., boiling and roasting processes.

\section{Materials and Methods}

\section{Samples Preparation}

Two types of meat samples were used, are beef chops and chicken breast meat with three different analyses involving raw meats, boiled meats and roasted meats. Beef chops $(m$. longissimus dorsi) and chicken breast meat $(m$. pectoralis major) were freshly bought from the slaughtermen. The preparation method was inspired by Sinanoglou et al., (2018). For raw meat analysis, the meat was packed and stored at $-18{ }^{\circ} \mathrm{C}$ of frozen storage. The boiled meats were prepared by boiling in hot water $\left(100{ }^{\circ} \mathrm{C}\right)$ for 30 minutes $(25 \pm 5)$ for beef chops and 15 minutes $(10 \pm 5)$ for chicken breasts. At the end of every five minutes the extractive substances produced by meats were removed from boiling water $(\mathrm{Oz}$ et al., 2016). The roasted meats were cooked by using a kitchen type oven. The meat samples were cooked when the oven temperature reached $200{ }^{\circ} \mathrm{C}$ for 15 minutes and 9 minutes respectively. All cooked meat samples were processed until the internal core temperature of beef and chicken reached 77 ${ }^{\circ} \mathrm{C}$ (well-done) and $70{ }^{\circ} \mathrm{C}$ respectively using a digital thermometer (Oz et al., 2016; Utama et $a l ., 2018)$. The meat samples were packed and stored in a sealed vacuum-packed and moisture impermeable polyethylene plastics and stored at $-4{ }^{\circ} \mathrm{C}$ in a freezer for a five-day period. The meat samples were analysed for five days in a row using FT-IR, colour spectrophotometer, texture analyser, while the physical image analysis was used to study raw meat samples. 


\section{FTIR Characterisation}

All meat samples were cut into approximately $0.001 \mathrm{~g}$ and were characterised by using UATR Two-FTIR spectrometer (Perkin Elmer) in the absorbance mode of 4000 to $400 \mathrm{~cm}^{-1}$ at room temperature $\left(24^{\circ} \mathrm{C}\right)$. The spectra were triplicated and recorded. Meat samples were analysed every day in the five-day period. The characterisation by FT-IR spectra was studied in two parts: (1) differentiate types of meat samples based on main functional groups existence, (2) interpret major and minor intensities of the obtained FTIR spectra based on increasing storage period (Sinanoglou et al., 2018).

\section{Colour Measurement}

All meat samples were weighed to approximately 5-10 $\mathrm{g}$ in individual sample cups. Meats were minced and compressed to obtain a smooth surface inside the cup and evaluated using a colour spectrophotometer (Hunter Lab 4500L). Colour spectrophotometer gave direct tristimulus of $\mathrm{L}^{*}$ (lightness), $\mathrm{a}^{*}$ (redness) and $\mathrm{b}^{*}$ (yellowness) values. $\mathrm{L}^{*}$ signifies the lightness of the color, $\mathrm{a}^{*}$ represents a measurement from red (+) to green (-) colour, and $b^{*}$ represents a measurement from yellow $(+)$ to blue (-) colour. The obtained tristimulus data were triplicated and expressed in mean \pm standard deviation.

\section{Texture Analysis}

All meat samples were cut into small cubes with measurement of $2 \mathrm{~cm} \times 2 \mathrm{~cm} \times 2 \mathrm{~cm}$ (height $\times$ width $\times$ length) and analysed using a texture analyser (Stable Micro System TA.XT Plus). The texture analyser was calibrated first and the meats were loaded in the T.A. System Software. The meat samples were placed parallel to the surface of the penetration point. The probe chosen was flat-faced cylindrical probe $5 \mathrm{~mm}$, with pre-test speed of $10 \mathrm{~mm} / \mathrm{sec}$, test speed of $2 \mathrm{~mm} / \mathrm{sec}$ and post-test speed of $10 \mathrm{~mm} / \mathrm{sec}$. The data of hardness or force required to compress samples were triplicated (Peleg, 2019). The results of texture profile analysis (TPA) were triplicated and averaged with standard deviation.

\section{Physical Image Analysis}

Physical image analysis was determined by using a Canon digital camera by placing $3 \mathrm{~cm} \times$ $2 \mathrm{~cm}$ (length $\times$ height) of raw meat samples (beef and chicken meat) (Sinanoglou et al., 2018).

\section{Results and Discussion \\ FTIR Characterization}

All meat samples were analysed using FT-IR spectroscopy in the mid-infrared region and wavelength of 4000 to $400 \mathrm{~cm}^{-1}$. Figures 1(a), 1(b) and 1(c) (in Appendix) show the FT-IR spectra of raw meats (beef and chicken), boiled meats (beef and chicken) and roasted meats (beef and chicken), respectively. The purpose is to determine the main functional groups that existed and related to the compositional changes of meats. Similar FTIR spectra showing a similar compositional of the nutritional content of meat samples was observed. The wide absorption band at the range of 3500 to $3000 \mathrm{~cm}^{-1}$ are is due to $\mathrm{O}-\mathrm{H}$ and $\mathrm{N}-\mathrm{H}$ symmetric stretching vibration of alcohols and amide or proteins, respectively. Besides, a strong band at $3300 \mathrm{~cm}^{-1}$ is referred to as amide $\mathrm{A}$ and amide $\mathrm{B}$ bands. The amide A band is contributed to the $\mathrm{N}-\mathrm{H}$ vibration, and the amide $\mathrm{B}$ band is the first overtone of amide II vibration. The changes in this range of wavelengths are related to changes in structural secondary protein within meats. These findings are similar to Sinanoglou et al. (2018), Petracci \& Berri (2017) and Barth (2007).

The weak absorptions bands at 2950 to $2850 \mathrm{~cm}^{-1}$ are related to methyl and methylene groups' asymmetric and symmetric stretching of the carbonyl group of triglycerides' ester bond. These bands were the most significant in roasted meats and slightly intense in boiled meats. It shows that higher heating treatment causes more intense at 2950 to $2850 \mathrm{~cm}^{-1}$ as roasting used higher temperatures during the cooking process. The strong and sharp absorption band at the range of 1640 to $1634 \mathrm{~cm}^{-1}$ can be described as $\mathrm{C}=\mathrm{O}$ stretching vibration of amides $\mathrm{I}$. This peak is correlated with proteins adopting with $\beta$-sheets conformation and strong water absorption 
which will significantly overlap the amide I band (Herrero et al., 2017; Papadopoulou et al., 2011). The strong water absorption indicates the high moisture content of meat that influences the protein structure. The strong water absorptions will cause the meat to deuterate to prevent the protein structural changes. Despite the amide I band, the amide II band can determine the protein structural changes due to the intrusion of water bending at $1640 \mathrm{~cm}^{-1}$. The amide I absorption band which characterises the protein secondary structure is located in the region of 1648 to $1658 \mathrm{~cm}^{-1}$ and 1620 to $1640 \mathrm{~cm}^{-1}$ are associated with the $\alpha$-helix and the $\beta$-sheet protein structure, respectively (Yu., 2005). Therefore, the major protein structure content of both beef and chicken samples is $\beta$-sheet. Another sharp absorption band can be identified in the range of 1546 to $1550 \mathrm{~cm}^{-1}$. This is the combined vibration of the amino group $(\mathrm{N}-\mathrm{H})$ bending with the $\mathrm{C}-\mathrm{N}$ stretching of proteins. The peak at $1543 \mathrm{~cm}^{-1}$ represented $\mathrm{C}=\mathrm{O}$ stretching band and the scissoring band of $\mathrm{CH}_{2}$ groups. A similar result was observed by Herrero et al. (2017), where the strong absorption bands are affected by the amino group and the carbonyl group of proteins.

The weak absorbance bands at 1453 to $1399 \mathrm{~cm}^{-1}$ are related to the $\mathrm{C}-\mathrm{H}$ bending of alkyl chain methylene of lipid moieties. It also corresponds to $\mathrm{C}-\mathrm{H}$ asymmetric and symmetric stretching vibrations of protein moieties, respectively. Additionally, bands appearing in 1400 to $1200 \mathrm{~cm}^{-1}$ region can be attributed to bending vibrations of $\mathrm{CH}_{2}$ and $\mathrm{CH}_{3}$ aliphatic groups (Herrero et al., 2017). Ammor et al., (2009) found that the minor intensity peaks observed at $1458 \mathrm{~cm}^{-1}$ are related to scissoring of $\mathrm{CH}_{2}$ of fats. Moreira and co-workers (2018) proved that absorption bands at $1458 \mathrm{~cm}^{-1}$ are due to $\mathrm{C}-\mathrm{H}$ bending and stretching of methylene $\left(\mathrm{CH}_{2}\right)$ and methyl $\left(\mathrm{CH}_{3}\right)$ groups present in fats within the meat. Minor peaks at $1398 \mathrm{~cm}^{-1}$ and the peak at 1315 to $1303 \mathrm{~cm}^{-1}$ are related to stretching of C-N and $\mathrm{C}-\mathrm{O}$, bending of $\mathrm{N}-\mathrm{H}$ and $\mathrm{O}=\mathrm{C}-\mathrm{N}$ bending of amide III. The minor intensity peak observed at 1170 to $1154 \mathrm{~cm}^{-1}$ is attributed to the $\mathrm{C}-\mathrm{O}$ stretching of proteins and triglycerides. The region can also be associated with $\mathrm{C}-\mathrm{O}$ and $\mathrm{C}-\mathrm{C}$ stretching vibrations due to the presence of carbohydrates. At 1240 and $1083 \mathrm{~cm}^{-1}$, there are $\mathrm{P}=\mathrm{O}$ symmetric and asymmetric which contributed to phospholipids and nucleic acids. The absorption band at 1080 $\mathrm{cm}^{-1}$ contributed as carbohydrate moieties and in the case of meats, it can represent glycogen (Sinanoglou et al., 2018). Table 1 tabulated the summary of functional groups corresponding to the FTIR spectra for all meat samples.

Furthermore, the spectra of meat samples showed the absorbance bands of higher intensities at 3500 to $3000 \mathrm{~cm}^{-1}, 2950$ to 2920 $\mathrm{cm}^{-1}, 2852$ and $1744 \mathrm{~cm}^{-1}$. It seems that beef meat has a higher lipid content compared to chicken meat as the beef spectra show higher intensities than chicken meat spectra. Moreover, the band at 3500 to $3000 \mathrm{~cm}^{-1}$ is associated with the vibration of the olefin group, which is characterised by the higher content of unsaturated fatty acids (Guntarti et al., 2015). Additionally,

Table 1: Summary of functional groups in meat samples

\begin{tabular}{cl}
\hline Wavenumber $\left(\mathbf{c m}^{-1}\right)$ & \multicolumn{1}{c}{ Functional groups } \\
\hline $3500-3000$ & $\begin{array}{l}\text { O-H, N-H symmetric stretching vibration of alcohols \& amide of proteins, strong } \\
\text { water absorption, O-H }\end{array}$ \\
\hline 3300 & Amide A and amide B \\
\hline $2950-2850$ & Methyl \& methylene of C=O of triglycerides \\
\hline $1634-1640$ & $\mathrm{C}=\mathrm{O}$ stretching vibration of amides \\
\hline $1546-1550$ & $\mathrm{C}=\mathrm{O}$ stretching \& scissoring band of $\mathrm{CH}_{2}$ \\
\hline 1240 & $\mathrm{P}=\mathrm{O}$ symmetric \& asymmetric of phospholipids \& nucleic acids \\
\hline
\end{tabular}


beef meat has higher protein content than chickens, as the spectra of beef showed higher intensities at 1450,1395 , and 1170 to $1154 \mathrm{~cm}^{-1}$ than the ones of the chicken meat samples. In this sense, the adsorption bands at 1627 and $1541 \mathrm{~cm}^{-1}$, which are characteristics of the protein exhibited a higher signal in the spectra of beef meat than in those of the chicken ones. A similar observation was found by Sinanoglou et al (2018) who studied on turkey and pork hams. The spectra of the chicken obtained significantly higher intensities at 1040 to $1020 \mathrm{~cm}^{-1}$ than the beef, which is indicative of higher carbohydrate content.

\section{Effect of Frozen Storage Towards Meat Quality by FT-IR Interpretation}

To monitor the quality of all meat in frozen storage, a comparative analysis was carried out where the meat samples were analysed every day in a five-day period. The analysis comprises ef the selected range of wavelengths consisting of significant intensity peaks for all types of different samples that were used.

Based on Figures 2(a) and 2(b) (Appendix), it can be observed that the FTIR spectra of raw meat samples (beef and chicken) showed a significant decrease at $3500-3000 \mathrm{~cm}^{-1}$. The bands are correlated with olefin group vibration which indicates unsaturated fatty acid contents (Sinanoglou et al., (2018). The decrease in those absorbance bands confirmed that there is a partial reduction of unsaturated fatty acids within meat samples. The slightly increased intensities at $2990-2880 \mathrm{~cm}^{-1}$ from Day 1 to Day 5 in raw meat samples correspond to methyl and methylene groups' asymmetric and symmetric stretching of fatty acids. These changes may suggest that there is a degradation of triglycerides and an increase in the hydrolysis process resulting in the accumulation of free fatty acids. The freezing storage may suppress triglycerol acyl hydrolases that activate lipid hydrolysis, arising to free fatty acids, dimonoglycerides and monoglycerides (Liu \& Kokare, 2016).

Moreover, the decrease at the intensity peaks of $1634-1630 \mathrm{~cm}^{-1}$ followed with the other intensities peak at $1550-1540 \mathrm{~cm}^{-1}$ is probably due to the presence of partial protein rupture representing the stretching vibration of $\mathrm{C}=\mathrm{O}$ and bending vibration of $\mathrm{N}-\mathrm{H}(\mathrm{Yu}, 2005)$. The decreasing of minor intensities peaks between 1450-1440 $\mathrm{cm}^{-1}$ and 1399-1395 $\mathrm{cm}^{-1}$ within five days corresponds to the reducing of $\mathrm{C}-\mathrm{H}$ bending of alkyl chain methylene of lipid moieties and $\mathrm{C}-\mathrm{H}$ asymmetric and symmetric stretching vibrations of protein moieties respectively. Meanwhile, the reducing intensities at 1245 to $1240 \mathrm{~cm}^{-1}$ marginally throughout freezing storage indicates that $\mathrm{P}=\mathrm{O}$ absorption of nucleic acids reluctantly decreased due to freezing storage (Rahman et al., 2018) and followed with slightly reducing intensities peak at 1174 to $1165 \mathrm{~cm}^{-1}$ and 1082 to $1075 \mathrm{~cm}^{-1}$ as an increasing storage period. The intensity of 1174 to $1165 \mathrm{~cm}^{-1}$ decreased from day 1 to day 2 but remained constant in the next remaining three days. The intensities are associated with $\mathrm{C}=\mathrm{O}$ and $\mathrm{C}-\mathrm{O}$ stretching of carbonyl and ether bonds of triglycerides and the decrease probably means lessening of the triglyceride content in meat samples (Sinanoglou et al., 2018).

Figures 2(c) and 2(d) (Appendix) show the difference of FTIR spectra interpretation for boiled meats. It shows that as days of frozen storage increased, boiled meat samples did not experience any significant changes in their chemical properties. Most of the intensity peaks from 3500 to $3000 \mathrm{~cm}^{-1}, 1634$ to $1630 \mathrm{~cm}^{-1}$ and 1550 to $1540 \mathrm{~cm}^{-1}$ in both meat samples showed stagnant in those five days of storage where all of the chosen intensity peak range did not show any extreme differences or changes in those five days. This can also be seen in the FTIR spectra interpretation of roasted meats in Figures 2(e) and 2(f) (Appendix) where it exhibited a stationary intensity peak within five days of frozen storage. However, at 2990-2880 $\mathrm{cm}^{-1}$, roasted meats exhibit a higher absorbance than in the boiled meats. In this case, there was a higher chance for a high amount of carbonyl group methyl and methylene stretching in roasted meats. There were no previous findings for this comparative analysis of boiled meat and roasted meat in frozen storage. However, it 
can be concluded that frozen storage of cooked meat does not give any effects to its chemical properties. The cooking of meats would retain the quality of meats by un-disturbing the chemical composition of meats thus maintaining the shelf life of meats compared to the unprocessed meats. Table 2 tabulated the summarisation of intensity peak changes towards the frozen storage effect.

\section{Colour Measurement}

The colour measurement of meat samples was analysed using a colour spectrophotometer. Table 3 shows the values of the tristimulus of $\mathrm{L}^{*}$ (lightness), $\mathrm{a}^{*}$ (redness) and $\mathrm{b}^{*}$ (yellowness) of meat samples within a five-day period frozen storage. It shows that the values of $\mathrm{L}^{*}$ in all raw meat samples were significantly higher in Day 1 compared to Day 5. The $\mathrm{L}^{*}$ values in Day 1 of raw beef and chicken meats are $38.63 \pm 0.230$ and $63.35 \pm 0.044$, respectively. Eventually, both samples exhibit a slight decrease in $\mathrm{L}^{*}$ values until Day 5 of frozen storage, where the $\mathrm{L}^{*}$ values are decreased to $34.79 \pm 0.089$ (raw beef) and $58.99 \pm 0.116$ (raw chicken), respectively. A decrease of $\mathrm{a}^{*}$ values of meat samples was from Day 1 which exhibited $11.71 \pm 0.026$ (raw beef) and $8.91 \pm 0.021$ (raw chicken), and on the $5^{\text {th }}$ day exhibited $10.36 \pm 0.120$ (raw beef) and 7.3 \pm 0.050 (raw chicken). Likewise, the $b^{*}$ values showed a similar trend with a slight reduction from Day 1 where $6.82 \pm 0.015$ (raw beef) and $14.90 \pm 0.021$ (raw chicken) until Day 5 where $4.08 \pm 0.046$ (raw beef) and $11.56 \pm 0.090$ (raw chicken), respectively.

Besides that, the $\mathrm{L}^{*}$ values of boiled meat showed an increase from Day 1 to Day 5. The $\mathrm{L}^{*}$ values of boiled meats are $43.98 \pm 0.030$ (boiled beef) and $72.41 \pm 0.040$ (boiled chicken) in Day 1 and increased to $44.83 \pm 0.020$ (boiled beef) and $74.64 \pm 0.040$ (boiled chicken) in the Day 5 . The increase was also shown in $b^{*}$ value of both boiled meat samples, where $10.30 \pm 0.300$ (boiled beef) and $15.95 \pm 0.040$ (boiled chicken) in Day 1 to $10.66 \pm 0.010$ (beef boiled) and 16.47 \pm 0.290 (chicken boiled) in Day 5, respectively. However, $a^{*}$ values for boiled meats decreased from Day 1, with values of $6.96 \pm 0.006$ (boiled beef) and $2.35 \pm 0.010$ (boiled chicken) to $5.84 \pm 0.010$ (boiled beef) and $1.63 \pm 0.020$ (boiled chicken) at Day 5. The roasted meats also showed an increase of colour parameters $\mathrm{L}^{*}$ with $40.74 \pm 0.060$ (roasted beef) and 70.32 \pm 0.090 (roasted chicken) in Day 1 to $42.30 \pm$ 0.040 (roasted beef) and $71.12 \pm 0.040$ (roasted chicken) in Day 5. There are decreases in $a^{*}$ values from Day 1 to Day 5 with values of 0.35 \pm 0.010 to $0.022 \pm 0.010$ for roasted beef, and $1.54 \pm 0.020$ to $1.10 \pm 0.050$ for roasted chicken, respectively. While $b^{*}$ values of roasted meats showed a slight increase from Day 1 to Day 5

Table 2: Changes in intensity peak in a five-day storage

\begin{tabular}{ccl}
\hline Wavenumber $\left(\mathbf{c m}^{-1}\right)$ & Functional groups & \multicolumn{1}{c}{ Interpretation } \\
\hline $3500-3000$ & O-H, N-H & $\begin{array}{l}\text { Decrease in unsaturated fatty acid contents; } \\
\text { partial reduction of unsaturated fatty acids within meat } \\
\text { samples }\end{array}$ \\
\hline $2990-2880$ & $\begin{array}{c}\text { Methyl \& } \\
\text { methylene of C=O }\end{array}$ & $\begin{array}{l}\text { Increase in the?? represents fatty acids } \\
\text { Degradation of triglycerides \& increase of hydrolysis } \\
\text { process resulting in the accumulation of free fatty acids }\end{array}$ \\
\hline $1634-1630$ & $\mathrm{C}=\mathrm{O}$ & Represent partial protein rupture \\
\hline $1550-1540$ & $\mathrm{C}=\mathrm{O}$ & Represent partial protein rupture \\
\hline $1450-1400$ & $\mathrm{C}-\mathrm{H}$ & Decrease in lipid moieties \\
\hline $1399-1395$ & $\mathrm{C}-\mathrm{H}$ & Decrease in protein moieties \\
\hline $1245-1240$ & $\mathrm{P}=\mathrm{O}$ & Decrease of nucleic acids \\
\hline $1174-1165$ & $\mathrm{C}=\mathrm{O}$ & Decrease of triglycerides \\
\hline $1082-1075$ & $\mathrm{C}-\mathrm{O}$ & Decrease of triglycerides \\
\hline
\end{tabular}


with $10.93 \pm 0.050$ (roasted beef) and $13.12 \pm$ 0.090 (roasted chicken) to $11.73 \pm 0.007$ (roasted beef) and $13.72 \pm 0.030$ (roasted chicken). It can be simplified that the $\mathrm{L}^{*}, \mathrm{a}^{*}$ and $\mathrm{b}^{*}$ values of raw meats decreased from Day 1 until Day 5. The boiled and roasted meats exhibited an increase in $\mathrm{L}^{*}$ and $\mathrm{b}^{*}$ values but a decrease in $a^{*}$ values within five days of storage. It can be revealed that the $L^{*}$ and $b^{*}$ values of raw meats are lower than boiled and roasted meats, while $a^{*}$ values of raw meats were significantly higher than the boiled and roasted meats. The results and findings for cooked meat correspond to the findings of Oz, et al. (2016).

The reduction $\mathrm{L}^{*}, \mathrm{a}^{*}$ and $\mathrm{b}^{*}$ values of raw meats from Day 1 until Day 5 are correlated with myoglobin content in meat muscle. Meat colour in both white meat and red meat is mostly determined by the amount of myoglobin, haemoglobin and cytochrome $\mathrm{C}$ catalase in skeletal muscle (Nathan et al., 2016; Yu et al., 2017). However, 80 to $90 \%$ of meat colour depends on myoglobin content. Frozen storage and increasing shelf life of meat samples may give an impact on the stability of myoglobin content. It can also be described that after freezing storage meat for a long time, a high concentration of metmyoglobin gives the meat an undesirable brown colour and lessens the red colour of meat. This is the cause of changes of both $a^{*}$ and $b^{*}$ values of meat samples. Similar results have been found with frozen storage of fresh beef (Pietrasik \& Janz, 2009), poultry meat (Leygonie et al., 2012) and fresh lamb (Belles et al., 2018). The colour changes that occur are caused by the deterioration of the globin moiety of myoglobin during storage. Myoglobin will be more susceptible to autoxidation when deterioration occurs, leading to a subsequent amount of discoloration within the meat. The accumulation of metmyoglobin within meat during storage can explain the reduction of $\mathrm{a}^{*}$ value of meat samples (Bekhit et al., 2007). Changes in $b^{*}$ values are mostly caused by the metmyoglobin content as well and lipid oxidation (Xiong, 2000), while the decreasing $\mathrm{L}^{*}$ value is caused by decreased water retention, resulting in lower surface light reflectivity (Hughes et al., 2014).

The colour of meat samples can be also affected by the cooking method. The boiling method is one of many cooking methods preferred by meat consumers. The colour of the boiled sample did not show any significant difference within five days of storage. However, it can be seen that the $\mathrm{L}^{*}$ and $\mathrm{b}^{*}$ parameters for boiled and roasted meats are higher than the raw meats (Table 3), while a* values of boiled and roasted meats are lower than the raw meats. During the time of cooking the meat, the globin gives the colour to fresh meat denatured forming haemoglobin (Aberle et al., 2001). This leads to subsequent decrease in $\mathrm{a}^{*}$ values. Besides, a lower average of $\mathrm{L}^{*}$ values in roasted meat was correlated with dry heat treatment applied while a higher average of $\mathrm{L}^{*}$ values in boiled meat represents moist heat treatment (Oz and Zikirov, 2015; Utama et al., 2018). The decrease in $a^{*}$ value of roasted and boiled meat indicates the denaturation of myoglobin content as it is usually correlated with the amount of oxymyoglobin. Therefore, a decrease in $\mathrm{a}^{*}$ value also indicates the denaturation the myoglobin pigments. Similar findings were obtained by Sanzhez del Pulgar et al. (2012) as their research also obtained a decrease in $\mathrm{a}^{*}$ values of beef. Choi et al., (2016) also obtained similar results for boiled chicken breast meats. The increased $b^{*}$ values of boiled and roasted meats are noted more than raw meat samples and this indicates yellow colour intensity. The yellow colour on meat is still unexplained. However, findings by Wei et al., (2017) also have shown similar results, where the $b^{*}$ value increased and was correlated with increased lipid oxidation.

Based on the findings, it shows that the value of $\mathrm{L}^{*}, \mathrm{a}^{*}$ and $\mathrm{b}^{*}$ of raw meat samples decreased from Day 1 of frozen storage until Day 5 These changes were caused by the effect of frozen storage on the raw meat samples. The $\mathrm{L}^{*}, \mathrm{a}^{*}$ and $\mathrm{b}^{*}$ values of boiled meat samples during the five days of storage did not give any significant difference. This shows that the colour measurement of boiled and roasted meat 
Table 3: Colour measurement values $\left(\mathrm{L}^{*}, \mathrm{a}^{*}, \mathrm{~b}^{*}\right)$ of raw, boiled and roasted beef and chicken meats

\begin{tabular}{|c|c|c|c|}
\hline \multicolumn{4}{|c|}{ Raw Beef } \\
\hline Time (day) & $\mathrm{L}^{*}$ & $a^{*}$ & $b^{*}$ \\
\hline 1 & $38.63 \pm 0.230$ & $11.71 \pm 0.026$ & $6.82 \pm 0.015$ \\
\hline 2 & $37.79 \pm 0.220$ & $11.37 \pm 0.015$ & $5.03 \pm 0.017$ \\
\hline 3 & $37.18 \pm 0.046$ & $11.24 \pm 0.034$ & $4.91 \pm 0.023$ \\
\hline 4 & $36.79 \pm 0.075$ & $10.87 \pm 0.110$ & $4.72 \pm 0.026$ \\
\hline 5 & $34.79 \pm 0.089$ & $10.36 \pm 0.120$ & $4.08 \pm 0.046$ \\
\hline \multicolumn{4}{|c|}{ Raw Chicken } \\
\hline Time (day) & $\mathrm{L}^{*}$ & $a^{*}$ & $b^{*}$ \\
\hline 1 & $63.35 \pm 0.044$ & $8.91 \pm 0.021$ & $14.90 \pm 0.021$ \\
\hline 2 & $62.53 \pm 0.100$ & $7.72 \pm 0.050$ & $12.88 \pm 0.040$ \\
\hline 3 & $61.56 \pm 0.030$ & $7.66 \pm 0.005$ & $12.64 \pm 0.010$ \\
\hline 4 & $59.03 \pm 0.006$ & $7.45 \pm 0.04$ & $11.82 \pm 0.060$ \\
\hline 5 & $58.99 \pm 0.116$ & $7.30 \pm 0.05$ & $11.56 \pm 0.090$ \\
\hline \multicolumn{4}{|c|}{ Boiled Beef } \\
\hline Time (day) & $\mathrm{L}^{*}$ & $a^{*}$ & $b^{*}$ \\
\hline 1 & $43.98 \pm 0.030$ & $6.96 \pm 0.006$ & $10.30 \pm 0.300$ \\
\hline 2 & $44.00 \pm 0.140$ & $6.79 \pm 0.006$ & $10.66 \pm 0.010$ \\
\hline 3 & $44.47 \pm 0.050$ & $6.68 \pm 0.050$ & $11.01 \pm 0.150$ \\
\hline 4 & $44.71 \pm 0.020$ & $6.49 \pm 0.020$ & $11.12 \pm 0.040$ \\
\hline 5 & $44.83 \pm 0.020$ & $5.84 \pm 0.010$ & $11.66 \pm 0.010$ \\
\hline \multicolumn{4}{|c|}{ Boiled Chicken } \\
\hline Time (day) & $\mathrm{L} *$ & $a^{*}$ & $b^{*}$ \\
\hline 1 & $72.41 \pm 0.040$ & $2.35 \pm 0.010$ & $15.95 \pm 0.040$ \\
\hline 2 & $72.47 \pm 0.120$ & $2.24 \pm 0.050$ & $16.12 \pm 0.030$ \\
\hline 3 & $72.94 \pm 0.050$ & $2.06 \pm 0.030$ & $16.44 \pm 0.006$ \\
\hline 4 & $73.88 \pm 0.020$ & $1.66 \pm 0.006$ & $16.46 \pm 0.020$ \\
\hline 5 & $74.64 \pm 0.040$ & $1.63 \pm 0.020$ & $16.47 \pm 0.290$ \\
\hline \multicolumn{4}{|c|}{ Roasted Beef } \\
\hline Time (day) & $\mathrm{L}^{*}$ & $a^{*}$ & $b^{*}$ \\
\hline 1 & $40.74 \pm 0.060$ & $0.350 \pm 0.010$ & $10.93 \pm 0.050$ \\
\hline 2 & $41.77 \pm 0.050$ & $0.032 \pm 0.010$ & $10.87 \pm 0.010$ \\
\hline 3 & $41.81 \pm 0.010$ & $0.029 \pm 0.030$ & $11.38 \pm 0.030$ \\
\hline 4 & $41.80 \pm 0.030$ & $0.025 \pm 0.010$ & $11.69 \pm 0.040$ \\
\hline 5 & $42.30 \pm 0.040$ & $0.022 \pm 0.010$ & $11.73 \pm 0.070$ \\
\hline \multicolumn{4}{|c|}{ Roasted Chicken } \\
\hline Time (day) & $\mathrm{L}^{*}$ & $a^{*}$ & $b^{*}$ \\
\hline 1 & $70.32 \pm 0.090$ & $1.54 \pm 0.020$ & $13.12 \pm 0.090$ \\
\hline 2 & $70.51 \pm 0.070$ & $1.49 \pm 0.010$ & $13.57 \pm 0.010$ \\
\hline 3 & $70.75 \pm 0.020$ & $1.35 \pm 0.010$ & $13.62 \pm 0.030$ \\
\hline 4 & $70.87 \pm 0.050$ & $1.27 \pm 0.030$ & $13.67 \pm 0.010$ \\
\hline 5 & $71.12 \pm 0.040$ & $1.10 \pm 0.050$ & $13.72 \pm 0.030$ \\
\hline
\end{tabular}


samples was not affected by frozen storage but mostly by the cooking method treatment. The reasons are probably due to the denaturation of myoglobin during cooking resulting in no further changes exhibited during the frozen storage of cooked meats. The slight changes are increased in $\mathrm{L}^{*}$ and $\mathrm{b}^{*}$ and decreased in $\mathrm{a}^{*}$ in both boiled and roasted meat samples, perhaps as a result of freeze burn exhibit by meats. This finding supported FTIR analysis. To summarise, the raw meats indicate the colour changes which represent the differences in meat quality freshness. The colour of raw meats decreased and this shows the reduction of raw meats quality compared to the cooked meats.

\section{Texture Profile Analysis}

The mechanical and geometrical texture attributes of meats were evaluated using a texture analyser. The TPA was carried out to analyse the tenderness of meat samples. The results of the meat samples are shown in Table 4. Force needed to compress raw meat samples in Day 1 is higher than the raw meat samples in Day 5, recorded with $8.25 \pm 0.030 \mathrm{~N}$ (raw beef) to $7.89 \pm 0.050 \mathrm{~N}$ (raw beef) and $7.45 \pm$ $0.010 \mathrm{~N}$ (raw chicken) to $6.74 \pm 0.012 \mathrm{~N}$ (raw chicken), respectively. This indicates that as the storage period increased, the force needed for the compression of all raw meat samples decreased. The decline in force required was due to an increase in deterioration in the protein structure of raw meats.

As reported by Rhee et al. (2004), tenderness of meat may result from the degradation of structural proteins or protein patterns during freezing storage. Myosin degradation within meat muscle proteins is the main factor that may affect meat tenderness. Frozen storage also caused ice crystal formation within meat muscles, thus affecting meat tenderness. When the ice crystal formed within meat muscles, desiccation of the protein cell membrane will occur (Kang et al., 2014). The ice crystals may destroy the structure of meat as the water was frozen leading to a high concentration of solutes within the protein structure of meats. The ice crystals will attract water from intracellular to intercellular spaces leading to an excessive loss of moisture during the thawing process. The damaged muscle fibres do not reabsorb water upon thawing, thus a further loss of moisture to occurs. Wang et al (2020) stated that the tenderness of meats is affected mostly by the formation of ice crystals similar to this finding. As a consequence, the texture of meat may deteriorate due to an increase in the affluence of water-soluble nutritional components and also decrease the water holding capacity (WHC) of meat (Cho et al., 2014; Lagerstedt et al., 2008). In conformance with Huff-Lonergan \& Lonergan (2005), as stated that water loss is directly proportional to the WHC of muscle meat.

For boiled and roasted meat samples, with increasing frozen storage, the force needed was increased. Boiled meats exhibited an increase in tenderness from Day 1 until Day 5 with $9.56 \pm$ $0.001 \mathrm{~N}$ (boiled beef) to $10.12 \pm 0.08 \mathrm{~N}$ (boiled beef) and $9.45 \pm 0.030 \mathrm{~N}$ (boiled beef) to 9.96 $\pm 0.020 \mathrm{~N}$ (boiled chicken). Similarly, roasted meats also display similar findings with an increase in tenderness from Day 1 until Day 5. Roasted beef showed a total of $10.26 \pm 0.020 \mathrm{~N}$ and the roasted chicken exhibited the total force of $10.21 \pm 0.030 \mathrm{~N}$ on Day 1. Both exhibited an increase in tenderness on the last day with 11.35 $\pm 0.050 \mathrm{~N}$ for roasted beef and $10.61 \pm 0.060 \mathrm{~N}$ for roasted chicken, respectively. These findings were comparable to findings of Choi et al. (2016), in that increased tenderness is obtained for dry heat than moist heat treatment of meats.

The results of tenderness for cooked meats are higher than raw meats due to the toughening of muscle fibres and tenderness of connective tissue. Changes can occur in actin and myosin muscle fibre protein when heating. The peptide chains of amino acids undergo deformation and then reformed or coagulate back. This results in moisture loss and toughening of muscle fibres. However, it has been shown that moist heat gave a tenderising effect on connective tissue as a result of the alteration of collagen to gelatine. When heat is applied, collagen converted into 
Table 4: Texture profile analysis (TPA) of raw, boiled and roasted beef and chicken meats

\begin{tabular}{ccccccc}
\hline \begin{tabular}{l} 
Time of $\begin{array}{l}\text { Frozen } \\
\text { Storage } \\
\text { (Day) }\end{array}$ \\
\cline { 2 - 6 }
\end{tabular} & $\begin{array}{c}\text { Raw } \\
\text { beef }\end{array}$ & $\begin{array}{c}\text { Raw } \\
\text { chicken }\end{array}$ & $\begin{array}{c}\text { Boiled } \\
\text { beef }\end{array}$ & $\begin{array}{c}\text { Boiled } \\
\text { chicken }\end{array}$ & $\begin{array}{c}\text { Roasted } \\
\text { beef }\end{array}$ & $\begin{array}{c}\text { Roasted } \\
\text { chicken }\end{array}$ \\
\hline 1 & $8.25 \pm 0.030$ & $7.45 \pm$ & $9.56 \pm$ & $9.45 \pm$ & $10.26 \pm 0.020$ & $10.21 \pm 0.030$ \\
& & 0.010 & 0.001 & 0.030 & & \\
\hline 2 & $8.21 \pm 0.040$ & $7.40 \pm$ & $9.67 \pm$ & $9.53 \pm 0.090$ & $10.59 \pm 0.010$ & $10.32 \pm 0.010$ \\
& & 0.012 & 0.020 & & & \\
\hline 3 & $8.15 \pm 0.070$ & $7.29 \pm$ & $9.85 \pm$ & $9.78 \pm$ & $10.65 \pm 0.040$ & $10.46 \pm 0.050$ \\
& & 0.012 & 0.060 & 0.010 & & \\
\hline 4 & $8.12 \pm 0.010$ & $6.89 \pm$ & $9.96 \pm$ & $9.83 \pm$ & $10.87 \pm 0.030$ & $10.53 \pm 0.010$ \\
& & 0.012 & 0.010 & 0.030 & & \\
\hline 5 & $7.89 \pm 0.050$ & $6.74 \pm$ & $10.12 \pm$ & $9.96 \pm$ & $11.35 \pm 0.050$ & $10.61 \pm 0.060$ \\
& & 0.012 & 0.08 & 0.020 & & \\
\hline
\end{tabular}

water-soluble gel and muscle softens. A high softened connective tissue can be obtained by using moist heat treatment. Besides that, the harder texture of dry heated meat represents the denaturation of intramuscular collagen or changes in myofibrillar structure.

In conformance with that, Kaur et al. (2020) stated that denaturation of myofibrillar protein leads to meat toughening while tenderisation is caused by the solubilisation of connective tissue. This explained the higher average force in roasted meats than boiled meats. Freezing or frozen storage may also affect the tenderness of cooked meat. However, it is not as obvious as raw meat samples. Cooked meat has achieved its best tenderness resulting from the cooking method. Frozen-thawed cooked meats would not impact meat tenderness (Liu et al., 2020). The slight changes in the tenderness of meat in Table 4 probably indicate the ice crystal formation during frozen storage. It shows different tenderness of raw and cooked meats which is decreases and increases respectively due to the treatment process. In conclusion, this texture analysis is correlated with FTIR and colour measurement analysis. It inferred that the freshness of meat quality could be easily analysed.

\section{Physical Image Analysis}

Figures 3(a) and 3(b) (Appendix) show the images of raw beef and chicken meat surfaces in Day 1 and Day 5. The images were taken to analyse any significant changes in the meat muscles. There was no significant difference in meat muscles on the first day and the fifth day due to the low magnification of the digital camera used. However, according to Kim et al. (2015), the analysis of a meat structure using the hyperspectral image can show a significant change occurring during frozen storage. This might be due to frozen storage during those five days, indicating that ice crystal formation affects the muscle fibres in beef and chicken meat. As reported by Hong et al., (2005), frozen storage can result in the destruction of muscle fibres due to the formation of ice crystals of various sizes according to the freezing rate. A faster freezing rate results in smaller ice crystals while slower freezing rate leads to a bigger size of ice crystal formation. The larger the size of ice crystal, the more damage it can do to the meat muscle fibres. A smaller ice crystal formation will cause less physical damage to meat components while larger ones interrupt the muscle cells and cause exudation. Other than freezing, thawing has been proven to give effects on muscle fibres of meats. According to Taher and Farid (2001), minimum thawing can reduce degradation in quality of meats. 


\section{Conclusion}

This study was successfully implemented using the rapid and ease analysis methods, FT-IR spectroscopy, color spectrophotometer, texture analyser and physical image analysis for raw and cooked meats via boiling and roasting cooking methods throughout the five days of frozen storage. The FTIR analysis shows that there are significant changes in the composition of raw meat samples compared to cooked meat samples. The color measurement showed such substantial changes in meat samples within five days, where the freezing storage caused slight alterations for the colour parameters and partial degradation of some proteins in meat. The texture analysis shows significant difference in tenderness with different types of meat and cooking methods. However, the image analysis shows no significant changes in the textural surface of meat due to the conventional image analysis. It can be summarised that those methods applied were able to evaluate the differences in the quality of raw and cooked meats instead by of using laborious, costly and time-consuming analysis methods.

\section{Acknowledgements}

The authors would like to thank the Faculty of Applied Sciences and Technology, Universiti Tun Hussein Onn Malaysia for providing the facilities.

\section{References}

Aberle, E. D., Forrest, J. C., Gerrard, D. E. \& Mills, E.W. (2001). Principles of Meat Science. $4^{\text {th }}$ edition. Kendall/Hunt Publishing Corporation. Dubuque, Iowa.

Ammor, M. S., Argyri, A., \& Nychas, G.-J. E. (2009). Rapid Monitoring of The Spoilage of Minced Beef Stored Under Conventionally and Active Packaging Conditions Using Fourier Transform Infrared Spectroscopy in Tandem With Chemometrics. Meat Science, 81(3), 507-514. doi:https://doi. org/10.1016/j.meatsci.2008.10.015
Barth, A. (2007). Infrared Spectroscopy of Proteins. Biochimica et Biophysica Acta (BBA) - Bioenergetics, 1767(9), 10731101. doi:https://doi.org/10.1016/j.bbabio. 2007.06.004

Bekhit, A. E. D., Cassidy, L., Hurst, R. D., \& Farouk, M. M. (2007). Post-Mortem Metmyoglobin Reduction in Fresh Venison. Meat Science, 75(1), 53-60. doi:https://doi. org/10.1016/j.meatsci.2006.06.015

Bellés, M., Leal, L. N., Díaz, V., Alonso, V., Roncalés, P., \& Beltrán, J. A. (2018). Effect of Dietary Vitamin E on Physicochemical and Fatty Acid Stability of Fresh and Thawed Lamb. Food Chemistry, 239, 1$8 . \quad$ doi:https://doi.org/10.1016/j. foodchem.2017.06.076

Cheah, J. C. (2016). Protein Thaw Loss in Meat Systems: Biochemical Influence Towards Meat Authentication of Fresh Versus Thawed.

Chen, S. H., Fegan, N., Kocharunchitt, C., Bowman, J. P., \& Duffy, L. L. (2020). Changes of the Bacterial Community Diversity on Chicken Carcasses Through an Australian Poultry Processing Line. Food Microbiology, 86, 103350. doi:https://doi. org/10.1016/j.fm.2019.103350

Cho, S., Kang, G., Seong, P., Park, K., Kim, Y., Park, B., \& Kang, S. M. (2014). Effect of Thawing Method on Water-soluble Nutritional Components and Quality Properties of Hanwoo Beef.

Choi, Y.-S., Hwang, K.-E., Jeong, T.-J., Kim, Y.B., Jeon, K.-H., Kim, E.-M., Sung J-M., Kim H-W., \& Kim, C.-J. (2016). Comparative Study on the Effects of Boiling, Steaming, Grilling, Microwaving and Superheated Steaming on Quality Characteristics of Marinated Chicken Steak. Korean Journal for Food Science of Animal Resources, 36(1), 1-7. doi:10.5851/kosfa.2016.36.1.1

Dixit, Y., Casado-Gavalda, M. P., CamaMoncunill, R., Cama-Moncunill, X., Markiewicz-Keszycka, M., Cullen, P. J., 
\& Sullivan, C. (2017). Developments and Challenges in Online NIR Spectroscopy for Meat Processing. Comprehensive Reviews in Food Science and Food Safety, 16(6), 1172-1187. doi:10.1111/1541-4337.12295

Guntarti, A., Martono, S., Yuswanto, A., \& Rohman, A. (2015). FTIR Spectroscopy in Combination with Chemometrics for Analysis of Wild Boar Meat in Meatball Formulation. Asian Journal of Biochemistry, 10, 165-172. doi:10.3923/ajb.2015.165.172

Herrero, A. M., Carmona, P., JiménezColmenero, F. and Ruíz-Capillas, C. (2010). Applications of Vibrational Spectroscopy to Study Protein Structural Changes in Muscle and Meat Batter Systems. In Handbook of Vibrational Spectroscopy (eds J.M. Chalmers and P.R. Griffiths). doi:10.1002/0470027320.s8949

Hong, G. P., Park, S. H., Kim, J. Y., Lee, S.

K., \& Min, S.-G. (2005). Effects of TimeDependent High Pressure Treatment on Physico-Chemical Properties of Pork. Food science and biotechnology, 14, 808-812.

Huff-Lonergan, E., \& Lonergan, S. M. (2005). Mechanisms of Water-Holding Capacity of Meat: The Role of Postmortem Biochemical and Structural Changes. Meat Science, 71(1), 194-204. doi:https://doi. org/10.1016/j.meatsci.2005.04.022

Hughes, J. M., Oiseth, S. K., Purslow, P. P., \& Warner, R. D. (2014). A Structural Approach to Understanding the Interactions between Colour, Water-Holding Capacity and Tenderness. Meat Science, 98(3), 520532. doi:https://doi.org/10.1016/j. meatsci.2014.05.022

Jackman, P., Sun, D.-W., \& Allen, P. (2011). Recent Advances in the Use of Computer Vision Technology in The Quality Assessment of Fresh Meats. Trends in Food Science \& Technology, 22(4), 185197. doi:https://doi.org/10.1016/j.tifs.2011. 01.008

Kang, S. M., Kang, G., Seong, P.-N., Park, B., Kim, D., \& Cho, S. (2014). Evaluation of the Activities of Antioxidant Enzyme and Lysosomal Enzymes of the Longissimus dorsi Muscle from Hanwoo (Korean Cattle) in Various Freezing Conditions. Korean Journal for Food Science of Animal Resources, 34(6), 742-748. doi:10.5851/ kosfa.2014.34.6.742

Kaur, L., Hui, S. X., \& Boland, M. (2020). Changes in Cathepsin Activity during Low-Temperature Storage and Sous Vide Processing of Beef Brisket. Food science of animal resources, 40(3), 415-425. doi:10.5851/kosfa.2020.e21

Lagerstedt, Å., Enfält, L., Johansson, L., \& Lundström, K. (2008). Effect of Freezing on Sensory Quality, Shear Force and Water Loss in Beef M. longissimus dorsi. Meat Science, 80(2), 457-461. doi:https://doi. org/10.1016/j.meatsci.2008.01.009

Leygonie, C., Britz, T. J., \& Hoffman, L. C. (2012). Meat Quality Comparison Between Fresh and Frozen/Thawed Ostrich M. iliofibularis. Meat Science, 91(3), 364368. doi:https://doi.org/10.1016/j.meatsci. 2012.02.020

Liu, J., Ellies-Oury, M.-P., Chriki, S., Legrand, I., Pogorzelski, G., Wierzbicki, J., Farmer, L., Troy, D., Polkinghorne, R., \& Hocquette, J.-F. (2020). Contributions of Tenderness, Juiciness and Flavor Liking to Overall Liking of Beef in Europe. Meat Science, 168, 108190. doi:https://doi.org/10.1016/j. meatsci.2020.108190

Liu, X., \& Kokare, C.R. (2016). Chapter 11 Microbial Enzymes of Use in Industry.

Mancini, R. A., Kropf, D. H., Hunt, M. C., \& Johnson, D. E. (2005). Effects of Endpoint Temperature, $\mathrm{pH}$, and Storage Time on Cooked Internal Color Reversion of Pork Longissimus Chops. Journal of Muscle Foods, 16(1), 16-26. doi:10.1111/j.17454573.2004.07103. $\mathrm{x}$

Mi, Y., Bo, S., Il, K., Min, S.-G., SangYoon, L., Ji, J., \& Jung, C. (2015). Effects of Various Freezing and Thawing Techniques on Pork Quality in Ready-To-Eat Meals. African 
Journal of Food Science, 9, 525-533. doi:10.5897/AJFS2015.1358

Mutwakil, M. (2011). Meat Spoilage Mechanisms and Preservation Techniques: A Critical Review. American Journal of Agricultural and Biological Sciences, 6, 486-510. doi:10.3844/ ajabssp.2011.486.510

Oz, F., \& Zikirov, E. (2015). The Effects of SousVide Cooking Method on the Formation of Heterocyclic Aromatic Amines in Beef Chops. LWT - Food Science and Technology, 64(1), 120-125. doi:https://doi. org/10.1016/j.lwt.2015.05.050

Oz, F., Aksu, M. I., \& Turan, M. (2017). The Effects of Different Cooking Methods on Some Quality Criteria and Mineral Composition of Beef Steaks. Journal of Food Processing and Preservation, 41(4), e13008. doi:10.1111/jfpp.13008

Papadopoulou, O., Panagou, E. Z., Tassou, C. C., \& Nychas, G. J. E. (2011). Contribution of Fourier Transform Infrared (FTIR) Spectroscopy Data on the Quantitative Determination of Minced Pork Meat Spoilage. Food Research International, 44(10), 3264-3271. doi:https://doi. org/10.1016/j.foodres.2011.09.012

Peleg, M. (2019). The Instrumental Texture Profile Analysis Revisited. Journal of Texture Studies, 50(5), 362-368. doi:10.1111/jtxs. 12392

Petracci, M., \& Berri, C. (2017). Poultry Quality Evaluation Quality Attributes and Consumer Values.

Pietrasik, Z., \& Janz, J. A. M. (2009). Influence of Freezing and Thawing on the Hydration Characteristics, Quality, and Consumer Acceptance of Whole Muscle Beef Injected with Solutions of Salt and Phosphate. Meat Science, 81(3), 523-532. doi:https://doi. org/10.1016/j.meatsci.2008.10.006

Rahman, U. u., Sahar, A., Pasha, I., Rahman, S. u., \& Ishaq, A. (2018). Assessing the Capability of Fourier Transform Infrared Spectroscopy in Tandem with Chemometric
Analysis for Predicting Poultry Meat Spoilage. PeerJ, 6, e5376.

Rahman, U. u., Shahzad, T., Sahar, A., Ishaq, A., Khan, M. I., Zahoor, T., \& Aslam, S. (2016). Recapitulating the Competence of Novel \& Rapid Monitoring Tools for Microbial Documentation in Food Systems. LWT - Food Science and Technology, 67, 62-66. doi:https://doi.org/10.1016/j. lwt.2015.11.041

Rhee, M. S., Wheeler, T. L., Shackelford, S. D., \& Koohmaraie, M. (2004). Variation in Palatability and Biochemical Traits Within and Among Eleven Beef Muscles. Journal of Animal Science, 82(2), 534-550. doi: $10.2527 / 2004.822534 \mathrm{x}$

Rohman, A., Sismindari, Erwanto, Y., \& Che Man, Y. B. (2011). Analysis of Pork Adulteration in Beef Meatball using Fourier Transform Infrared (FTIR) Spectroscopy. Meat Science, 88(1), 91-95. doi:https://doi. org/10.1016/j.meatsci.2010.12.007

Sánchez del Pulgar, J., Gázquez, A., \& RuizCarrascal, J. (2012). Physico-Chemical, Textural and Structural Characteristics of Sous-Vide Cooked Pork Cheeks as Affected by Vacuum, Cooking Temperature, and Cooking Time. Meat Science, 90(3), 828835. doi:https://doi.org/10.1016/j.meatsci. 2011.11.024

Sinanoglou, V. J., Cavouras, D., Xenogiannopoulos, D., Proestos, C., \& Zoumpoulakis, P. (2018). Quality Assessment of Pork and Turkey Hams Using FT-IR Spectroscopy, Colorimetric, and Image Analysis. Foods (Basel, Switzerland), 7(9), 152. doi:10.3390/ foods7090152

Taher, B. J., \& Farid, M. (2001). Cyclic Microwave Thawing of Frozen Meat: Experimental and Theoretical Investigation. Chemical Engineering and Processing: Process Intensification, 40, 379-389. doi:10.1016/S0255-2701(01)00118-0 
Utama, D. T., Baek, K. H., Jeong, H. S., Yoon, S. K., Joo, S.-T., \& Lee, S. K. (2018). Effects of Cooking Method and Final Core-Temperature on Cooking Loss, Lipid Oxidation, Nucleotide-Related Compounds and Aroma Volatiles of Hanwoo Brisket. Asian-Australasian journal of animal sciences, 31(2), 293-300. doi:10.5713/ ajas. 17.0217

Wang, Y., Liang, H., Xu, R., Lu, B., Song, X., \& Liu, B. (2020). Effects of Temperature Fluctuations on The Meat quality and Muscle Microstructure of Frozen Beef. International Journal of Refrigeration, 116, 1-8. doi:https://doi.org/10.1016/j. ijrefrig.2019.12.025

Wei, R., Wang, P., Han, M., Chen, T., Xu, X., \& Zhou, G. (2017). Effect of Freezing on Electrical Properties and Quality of Thawed Chicken Breast Meat. Asian-Australasian journal of animal sciences, 30(4), 569-575. doi:10.5713/ajas.16.0435
Xiong, Y. L. (2000). Protein Oxidation and Implications for Muscle Food Quality (pp. 85-111). New York: John Wiley and Sons.

Yu, P. (2007). Protein Secondary Structures $(\alpha-$ helix and $\beta$-sheet) at a Cellular Level and Protein Fractions in Relation to Rumen Degradation Behaviours of Protein: A New Approach. British Journal of Nutrition, 94(5), 655-665. doi:10.1079/BJN20051532

Yu Q. P., Feng D. Y., Xiao J., Wu F., He X. J., Xia M. H., Dong T., Liu Y.H., Tan Z.E., Zou S.G., Zheng T., Ou X.H. \& Zuo J. J. (2017). Studies on Meat Color, Myoglobin Content, Enzyme Activities, and Genes Associated with Oxidative Potential of Pigs Slaughtered at Different Growth Stages. Asian-Australasian journal of animal sciences, 30(12), 1739-1750. doi:10.5713/ ajas. 17.0005

Zhou, G. H., Xu, X. L., \& Liu, Y. (2010). Preservation Technologies for Fresh Meat - A review. Meat Science, 86(1), 119128. doi:https://doi.org/10.1016/j.meatsci. 2010.04.033

\section{Appendix}

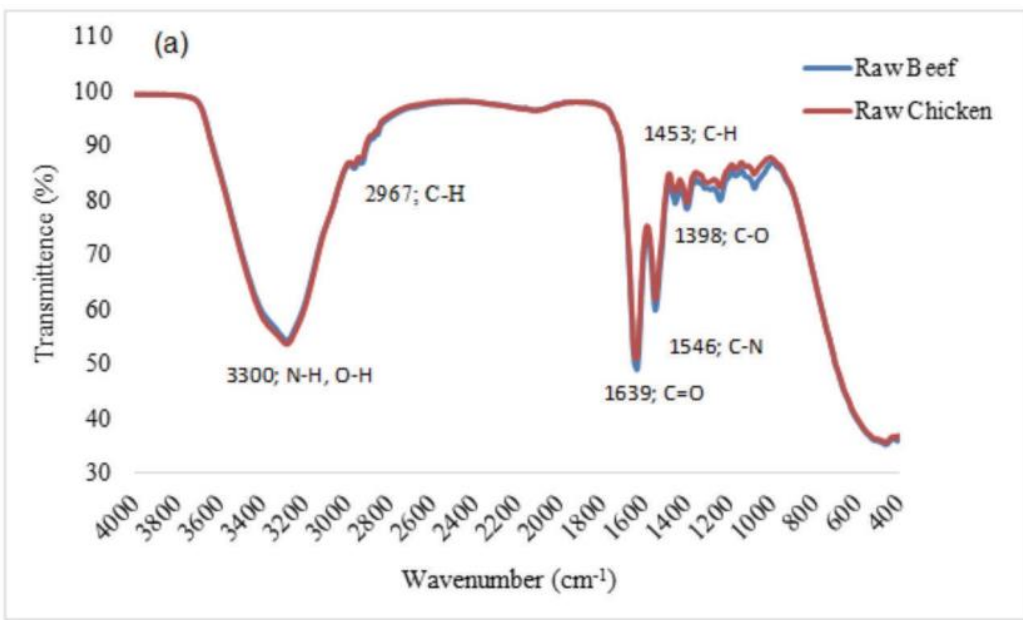




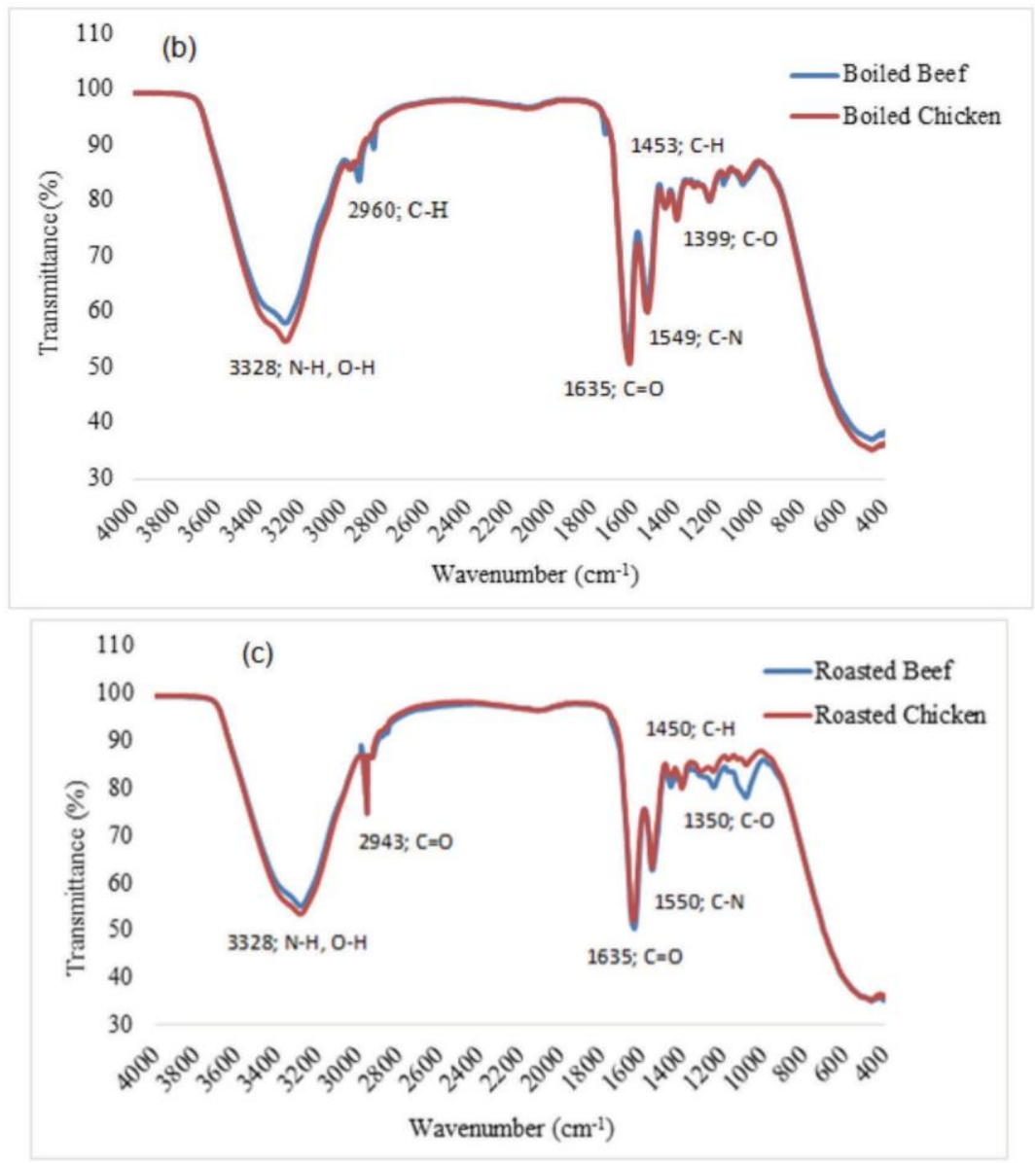

Figure 1: FT-IR spectra of (a) raw beef and chicken, (b) boiled beef and chicken and (c) roasted beef and chicken meats

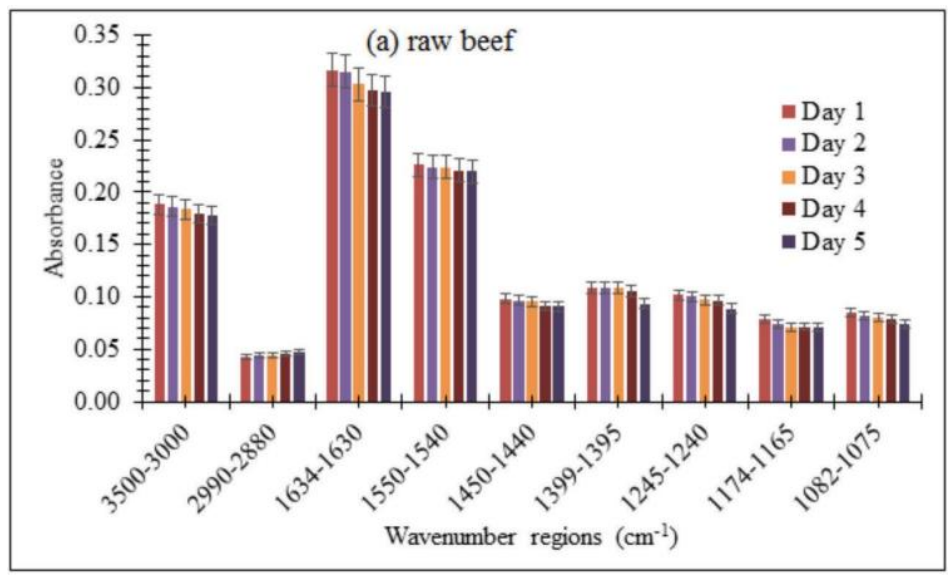



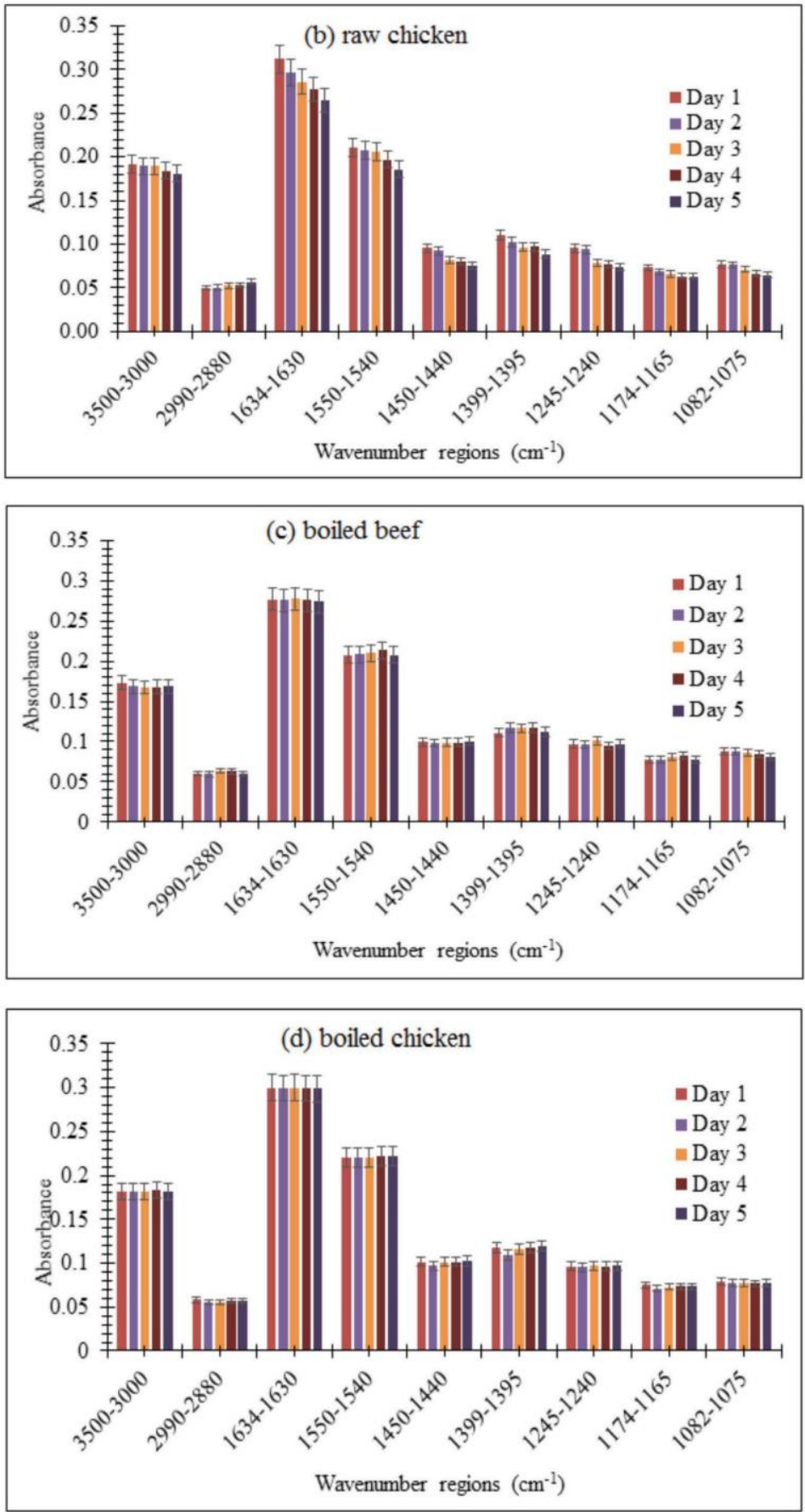

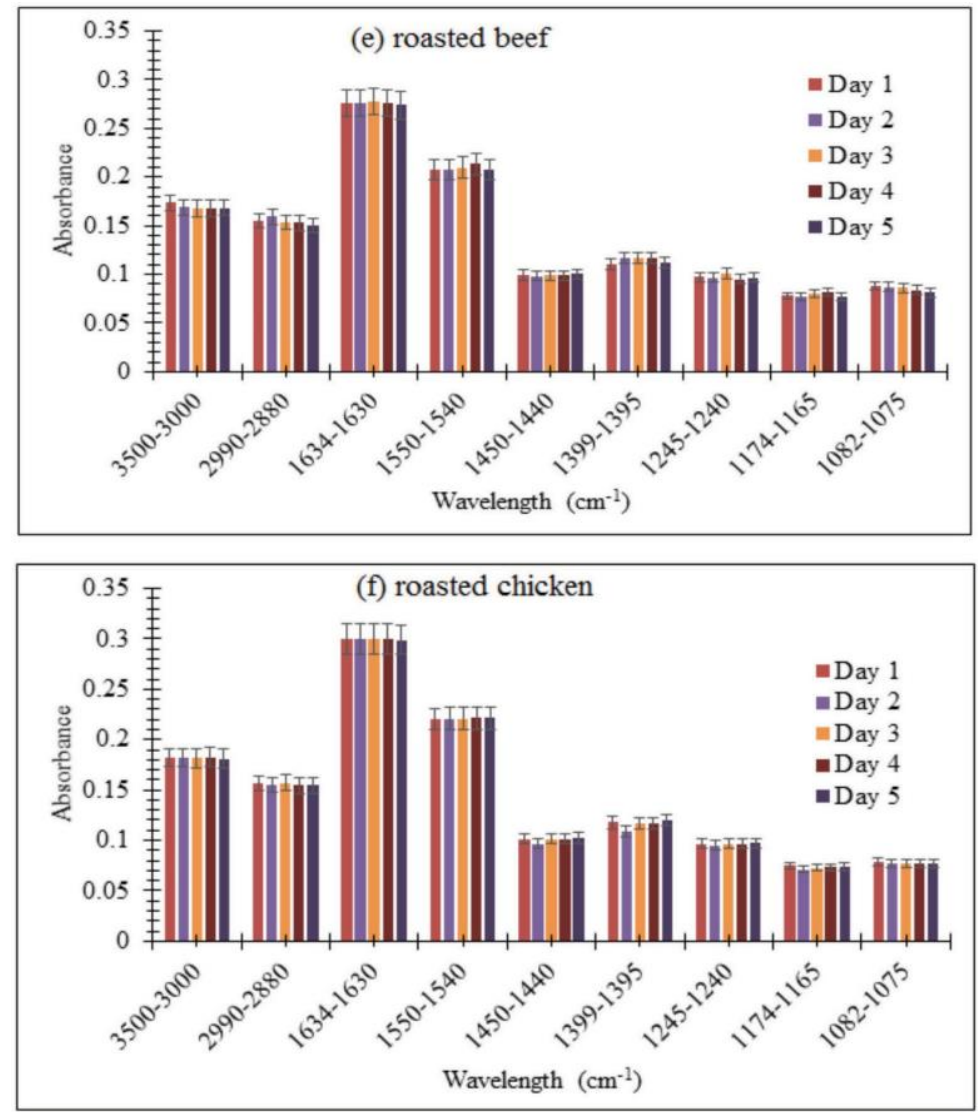

Figure 2: The FT-IR spectra interpretation of (a) raw beef; (b) raw chicken; (c) boiled beef; (d) boiled chicken; (e) roasted beef; (f) roasted chicken within five days storage

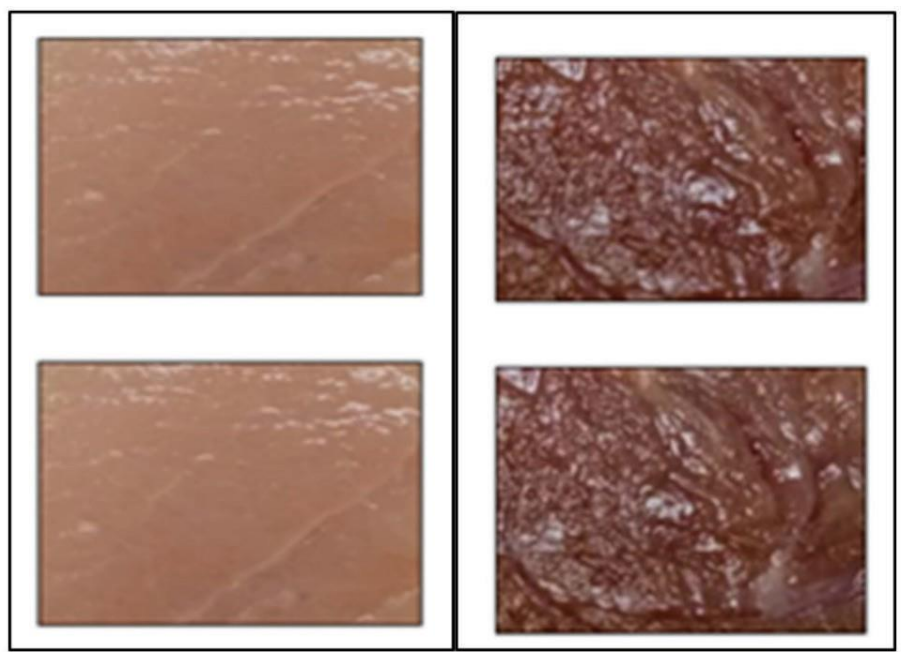

(a)

(b)

Figure 3: Image of (a) raw chicken and (b) raw beef in day 1 (above) and day 5 (below) 